\title{
Best Proximity Points for Some Classes of Proximal Contractions
}

\author{
Maryam A. Alghamdi, ${ }^{1}$ Naseer Shahzad, ${ }^{2}$ and Francesca Vetro ${ }^{3}$ \\ ${ }^{1}$ Department of Mathematics, King Abdulaziz University, Science Faculty for Girls, P.O. Box 4087, \\ Jeddah 21491, Saudi Arabia \\ ${ }^{2}$ Department of Mathematics, King Abdulaziz University, P.O. Box 80203, Jeddah 21859, Saudi Arabia \\ ${ }^{3}$ DEIM, Università Degli Studi di Palermo, Viale Delle Scienze, 90128 Palermo, Italy
}

Correspondence should be addressed to Naseer Shahzad; nshahzad@kau.edu.sa

Received 9 May 2013; Revised 11 August 2013; Accepted 11 August 2013

Academic Editor: E. Karapinar

Copyright (C 2013 Maryam A. Alghamdi et al. This is an open access article distributed under the Creative Commons Attribution License, which permits unrestricted use, distribution, and reproduction in any medium, provided the original work is properly cited.

Given a self-mapping $g: A \rightarrow A$ and a non-self-mapping $T: A \rightarrow B$, the aim of this work is to provide sufficient conditions for the existence of a unique point $x \in A$, called $g$-best proximity point, which $\operatorname{satisfies~} d(g x, T x)=$ $d(A, B)$. In so doing, we provide a useful answer for the resolution of the nonlinear programming problem of globally minimizing the real valued function $x \rightarrow d(g x, T x)$, thereby getting an optimal approximate solution to the equation $T x=g x$. An iterative algorithm is also presented to compute a solution of such problems. Our results generalize a result due to Rhoades (2001) and hence such results provide an extension of Banach's contraction principle to the case of non-self-mappings.

\section{Introduction}

A fundamental result in the fixed point theory is the Banach contraction principle, which has various nontrivial implications in many branches of pure and applied sciences.

Let $A$ and $B$ be nonempty subsets of a metric space $(X, d)$. We say that a non-self-mapping $T: A \rightarrow B$ is a contraction if there exists $k \in[0,1)$ such that, for all $x, y \in X$,

$$
d(T x, T y) \leq k d(x, y) .
$$

The Banach contraction principle asserts that if a selfmapping $T: X \rightarrow X$ is a contraction and $(X, d)$ is complete, then $T$ has a unique fixed point $x \in X$. This result was extended to other important classes of mappings and has numerous applications. For some important and interesting generalizations of Banach contraction principle, one can refer to $[1,2]$. The following notion of weakly contractive selfmapping was introduced by Alber and Guerre-Delabriere in [3].

Definition 1 (see [3]). Let $(X, d)$ be a metric space and let $A$ be a nonempty subset of $X$. A self-mapping $T: A \rightarrow A$ is said to be weakly contractive if

$$
d(T x, T y) \leq d(x, y)-\psi(d(x, y)),
$$

for all $x, y \in A$, where $\psi:[0,+\infty) \rightarrow[0,+\infty)$ is a continuous and nondecreasing function such that $\psi$ is positive on $(0,+\infty), \psi(0)=0$ and $\lim _{t \rightarrow+\infty} \psi(t)=+\infty$. If $A$ is bounded, then the infinity condition can be omitted.

Since all contractions are weakly contractive with the function $\psi(t)=(1-k) t$, the above theorem extends Banach contraction principle. In fact, the class of weakly contractive mappings lies between the classes of mappings 
called contraction ones and contractive ones $(d(T x, T y)<$ $d(x, y)$, for all $x, y \in X$ with $x \neq y$ ).

Generally, the solution of the equation $T x=x$, where $T: A \rightarrow X$ is a non-self-mapping, is called a fixed point of $T$. Hence, the condition $T(A) \cap A \neq \emptyset$ is necessary for the existence of a fixed point of $T$. Clearly, when $T(A) \cap A=\emptyset$, we have $d(x, T x)>0$, for all $x \in A$. In such a situation it is natural to search for a point $x \in A$ such that $x$ the is closest to $T x$ in some sense. The following well-known best approximation theorem, due to Fan [4], explores the existence of an approximate solution to the equation $T x=x$.

Theorem 2 (see [4]). Let $A$ be a nonempty compact convex subset of a normed linear space $X$ and let $T: A \rightarrow X$ be a continuous mapping. Then there exists $x \in A$ such that $\| x-$ $T x \|=d(T x, A)$.

The point $x \in A$ in Theorem 2 is called a best approximant of $T$ in $A$. Again, let $A, B$ be nonempty subsets of a metric space $(X, d)$ and let $T: A \rightarrow B$ be a non-selfmapping. A point $x_{0} \in A$ is called a best proximity point of $T$ if $d\left(x_{0}, T x_{0}\right)=d(A, B)$. Some interesting results in approximation theory can be found in [4-23].

The aim of this paper is to prove some best proximity point theorems for proximal contractions which are extensions of Banach contraction principle to the case of non-selfmappings. Precisely, given a self-mapping $g: A \rightarrow A$ and a non-self-mapping $T: A \rightarrow B$, this work focuses on $g$ best proximity point theorems for some classes of proximal contractions and a new family of mappings known as $g$-weak contractions. In fact, we provide sufficient conditions for the existence of a unique point $x \in A$, called $g$-best proximity point, which satisfies the condition $d(g x, T x)=d(A, B)$. Further, an iterative algorithm is furnished to determine an optimal approximate solution in the guise of a $g$-best proximity point. As a consequence, one can compute an optimal approximate solution to some coincidence point equations.

\section{Preliminaries}

Let $\mathbb{R}_{+}$denote the set of all positive real numbers and $\mathbb{N}$ denote the set of all positive integers. Let $A, B$ be two nonempty subsets of a metric space $(X, d)$. Let us fix the following notation which will be needed throughout this paper:

$$
\begin{aligned}
& A_{0}=\{x \in A: d(x, y)=d(A, B) \text { for some } y \in B\}, \\
& B_{0}=\{y \in B: d(x, y)=d(A, B) \text { for some } x \in A\},
\end{aligned}
$$

where $d(A, B)=\inf \{d(x, y): x \in A$ and $y \in B\}$. In [11], the authors discussed sufficient conditions which guarantee the nonemptiness of $A_{0}$ and $B_{0}$. Also, in [20], the authors proved that $A_{0}$ is contained in the boundary of $A$.

We denote by $\Psi$ the set of nondecreasing functions $\psi$ : $[0,+\infty) \rightarrow[0,+\infty)$ satisfying the following condition:

$(\psi 1) \lim _{n \rightarrow+\infty} \psi^{n}(t)=0$, for all $t>0$, where $\psi^{n}$ is the $n$th iterate of $\psi$.
Note that if $\psi \in \Psi$, then the following conditions hold:

$(\psi 2) \psi(t)<t$, for all $t>0 ; \psi(0)=0$; $\psi$ is continuous at $t=0$.

We denote by $\Phi$ the set of nondecreasing functions $\psi$ : $[0,+\infty) \rightarrow[0,+\infty)$ such that $\psi(t)=0$ if and only if $t=0$ and with $\Phi_{c}=\{\psi \in \Phi: \psi$ is continuous at $t=0\}$.

Definition 3 (see [21]). Let $A$ and $B$ be two nonempty subsets of a metric space $(X, d)$. A non-self-mapping $T: A \rightarrow B$ is said to be a proximal $\psi$-contraction of the first kind if

$$
d(u, T x)=d(A, B)=d(v, T y) \Longrightarrow d(u, v) \leq \psi(d(x, y)),
$$

for all $u, v, x, y \in A$, where $\psi \in \Psi$. If $\psi(t)=\alpha t$ for some $\alpha \in[0,1)$, then $T$ is said to be a proximal contraction of the first kind.

Definition 4 (see [21]). Let $A$ and $B$ be two nonempty subsets of a metric space $(X, d)$. A non-self-mapping $T: A \rightarrow B$ is said to be a proximal $\psi$-contraction of the second kind if

$$
\begin{aligned}
d(u, T x) & =d(A, B)=d(v, T y) \\
& \Longrightarrow d(T u, T v) \leq \psi(d(T x, T y)),
\end{aligned}
$$

for all $u, v, x, y \in A$, where $\psi \in \Psi$. If $\psi(t)=\alpha t$ for some $\alpha \in[0,1)$, then $T$ is said to be a proximal contraction of the second kind.

Definition 5 (see [14]). Let $A$ and $B$ be two nonempty subsets of a metric space $(X, d)$. A non-self-mapping $T: A \rightarrow B$ is said to be a weak proximal $\psi$-contraction of the first kind if

$$
\begin{aligned}
d(u, T x) & =d(A, B)=d(v, T y) \\
& \Longrightarrow d(u, v) \leq d(x, y)-\psi(d(x, y)),
\end{aligned}
$$

for all $u, v, x, y \in A$, where $\psi \in \Phi$.

Definition 6 (see [14]). Let $A$ and $B$ be two nonempty subsets of a metric space $(X, d)$. A non-self-mapping $T: A \rightarrow B$ is said to be a weak proximal $\psi$-contraction of the second kind if

$$
\begin{aligned}
d(u, T x) & =d(A, B)=d(v, T y) \\
& \Longrightarrow d(T u, T v) \leq d(T x, T y)-\psi(d(T x, T y)),
\end{aligned}
$$

for all $u, v, x, y \in A$, where $\psi \in \Phi$.

An example of a non-self-mapping $T$ that is weak proximal $\psi$-contraction of the first and second kinds can be found in [14].

The following result is a best proximity point theorem for weak proximal $\psi$-contraction of the first and second kinds.

Theorem 7 (see [14, Theorem 3.1]). Let $A$ and $B$ be closed subsets of a complete metric space $(X, d)$ such that $A_{0}$ and $B_{0}$ are nonvoid. Suppose that the mappings $g: A \rightarrow A$ and $T: A \rightarrow B$ satisfy the following conditions: 
(a) $T$ is a weak proximal $\psi$-contraction of the first and second kinds;

(b) $g$ is an isometry;

(c) $T\left(A_{0}\right) \subseteq B_{0}$;

(d) $A_{0} \subseteq g\left(A_{0}\right)$;

(e) $T$ preserves the isometric distance with respect to $g$.

Then, there exists a unique element $x^{*}$ in $A$ such that $d\left(g x^{*}, T x^{*}\right)=d(A, B)$. Further, for any fixed element $x_{0}$ in $A_{0}$, the iterative sequence $\left\{x_{n}\right\}$, defined by $d\left(g x_{n+1}, T x_{n}\right)=$ $d(A, B)$ for every $n \in \mathbb{N} \cup\{0\}$, converges to the element $x^{*}$.

Note that in Theorem 7, Sadiq Basha assumes that the function $\psi \in \Phi$ is continuous such that $\lim _{t \rightarrow+\infty} \psi(t)=+\infty$.

Let us define the notion of non-self- $g$-weakly contractive mappings as follows.

Definition 8 . Let $(X, d)$ be a metric space, let $A, B$ be two nonempty subsets of $X$, and let $g: A \rightarrow A$. A non-selfmapping $T: A \rightarrow B$ is said to be a $g$-weakly contractive mapping if there exists $\psi \in \Phi_{c}$ such that

$$
d(T x, T y) \leq d(g x, g y)-\psi(d(g x, g y)),
$$

for all $x, y \in A$.

Note that

$$
d(T x, T y) \leq d(g x, g y)-\psi(d(g x, g y))<d(g x, g y)
$$

if $x, y \in A$ with $g x \neq g y$; that is, $T$ is a $g$-contractive mapping.

Sankar Raj, in [22], introduced the notion called $P$ property, which was used to prove an extended version of Banach contraction principle.

Definition 9. Let $(A, B)$ be a pair of nonempty subsets of a metric space $(X, d)$ with $A_{0} \neq \emptyset$.

(i) The pair $(A, B)$ is said to have the $P$-property if and only if $d\left(x_{1}, y_{1}\right)=d(A, B)=d\left(x_{2}, y_{2}\right)$ implies $d\left(x_{1}, x_{2}\right)=d\left(y_{1}, y_{2}\right)$, where $x_{1}, x_{2} \in A_{0}$ and $y_{1}, y_{2} \in$ $B_{0}$ (see [22]).

(ii) The pair $(A, B)$ is said to have the weak $P$-property if and only if $d\left(x_{1}, y_{1}\right)=d(A, B)=d\left(x_{2}, y_{2}\right)$ implies $d\left(x_{1}, x_{2}\right) \leq d\left(y_{1}, y_{2}\right)$, where $x_{1}, x_{2} \in A_{0}$ and $y_{1}, y_{2} \in$ $B_{0}$ (see [24]).

It is easy to see that, for any nonempty subset $A$ of $X$, the pair $(A, A)$ has the $P$-property.

Definition 10. Let $A$ and $B$ be two nonempty subsets of a metric space $(X, d)$. Let $g: A \rightarrow A$ be a self-mapping and $T: A \rightarrow B$ a non-self-mapping. Then

(i) $g \in \mathscr{G}_{A}$ if $g$ is continuous and $d(x, y) \leq d(g x, g y)$, for all $x, y \in A$;

(ii) $T \in \mathscr{T}_{g}$ if $d(T x, T y) \leq d(\operatorname{Tg} x, \operatorname{Tg} y)$ for all $x, y \in A$;

(iii) $T$ is said to preserve (isometric) distance with respect to $g$ if $d(\operatorname{Tg} x, \operatorname{Tg} y)=d(T x, T y)$, for every $x, y \in A$ (see [9]).

\section{Best Proximity Point Theorems for Proximal Contractions}

In this section, we establish some results of best proximity point for proximal $\psi$-contractions and weak proximal $\psi$ contractions.

Theorem 11. Let $A$ and $B$ be two nonempty subsets of $a$ complete metric space $(X, d)$. Suppose that $A_{0}$ is nonempty and closed. Assume also that the mappings $T: A \rightarrow B$ and $g: A \rightarrow$ A satisfy the following conditions:
(a) $T$ is a proximal $\psi$-contraction of the first kind;
(b) $g \in \mathscr{G}_{A_{0}}$;
(c) $T\left(A_{0}\right) \subseteq B_{0}$;
(d) $A_{0} \subseteq g\left(A_{0}\right)$.

Then there exists a unique point $x \in A_{0}$ such that $d(g x, T x)=d(A, B)$. Moreover, for every $x_{0} \in A_{0}$ there exists a sequence $\left\{x_{n}\right\} \subseteq A$ such that $d\left(g x_{n+1}, T x_{n}\right)=d(A, B)$ for every $n \in \mathbb{N} \cup\{0\}$ and $x_{n} \rightarrow x$.

Proof. Let $x_{0} \in A_{0}$. Since $T\left(A_{0}\right) \subseteq B_{0}$ and $A_{0} \subseteq g\left(A_{0}\right)$, there exists $x_{1} \in A_{0}$ such that

$$
d\left(g x_{1}, T x_{0}\right)=d(A, B) .
$$

Again, for $x_{1} \in A_{0}$, there exists $x_{2} \in A_{0}$ such that

$$
d\left(g x_{2}, T x_{1}\right)=d(A, B) .
$$

By repeating this process, for $x_{n} \in A_{0}$, we can find $x_{n+1} \in A_{0}$ such that

$$
d\left(g x_{n+1}, T x_{n}\right)=d(A, B), \quad \forall n \in \mathbb{N} .
$$

Since $T$ is a proximal $\psi$-contraction of the first kind and $g \in$ $\mathscr{G}_{A_{0}}$, we have

$$
\begin{aligned}
d\left(x_{n+1}, x_{n}\right) & \leq d\left(g x_{n+1}, g x_{n}\right) \\
& \leq \psi\left(d\left(x_{n}, x_{n-1}\right)\right)
\end{aligned}
$$

for every $n \in \mathbb{N} \cup\{0\}$. Since $\psi$ is nondecreasing, we get by induction that

$$
d\left(x_{n+1}, x_{n}\right) \leq \psi^{n}\left(d\left(x_{1}, x_{0}\right)\right) .
$$

By the definition of $\psi$, letting $n \rightarrow+\infty$, we obtain that

$$
\lim _{n \rightarrow+\infty} d\left(x_{n+1}, x_{n}\right)=0 \text {. }
$$

We now prove that $\left\{x_{n}\right\}$ is a Cauchy sequence. Given that $\varepsilon>0$ there exists $n(\varepsilon) \in \mathbb{N}$ such that

$$
d\left(x_{n}, x_{n+1}\right)<\varepsilon-\psi(\varepsilon), \quad \forall n \geq n(\varepsilon) .
$$

Now, fix $m \geq n(\varepsilon)$ and we prove that

$$
d\left(x_{m}, x_{n+1}\right)<\varepsilon, \quad \forall n \geq m .
$$


Note that (17) holds if $n=m$, by (16). Assume that (17) holds for some $n \geq m$. Since $T$ is a proximal $\psi$-contraction of the first kind,

$$
\begin{aligned}
d\left(x_{m}, x_{n+2}\right) & \leq d\left(x_{m}, x_{m+1}\right)+d\left(x_{m+1}, x_{n+2}\right) \\
& \leq d\left(x_{m}, x_{m+1}\right)+d\left(g x_{m+1}, g x_{n+2}\right) \\
& \leq d\left(x_{m}, x_{m+1}\right)+\psi\left(d\left(x_{m}, x_{n+1}\right)\right) \\
& <\varepsilon-\psi(\varepsilon)+\psi(\varepsilon)=\varepsilon .
\end{aligned}
$$

This implies that (17) holds, for all $n \geq m$, and hence

$$
\lim _{m \rightarrow+\infty} d\left(x_{m}, x_{n+1}\right)=0 .
$$

That is, $\left\{x_{n}\right\}$ is a Cauchy sequence. By the completeness of $X$ and since $A_{0}$ is closed, we have $x_{n} \rightarrow x \in A_{0}$. Moreover, by the continuity of $g$, we have $g x_{n} \rightarrow g x$ and thus $g x \in A_{0}$, since $g x_{n} \in A_{0}$, for all $n \in \mathbb{N}$. On the other hand, since $x \in A_{0}$ and $T\left(A_{0}\right) \subseteq B_{0}$, there exists $z \in A$ such that

$$
d(z, T x)=d(A, B)
$$

Clearly $z \in A_{0}$. Again, since $T$ is a proximal $\psi$-contraction of the first kind, we get

$$
d\left(z, g x_{n+1}\right) \leq \psi\left(d\left(x, x_{n}\right)\right) \leq d\left(x, x_{n}\right),
$$

for all $n \in \mathbb{N}$. Letting $n \rightarrow+\infty$, we obtain that $d\left(z, g x_{n+1}\right) \rightarrow$ 0 and then $z=g x$. This implies that

$$
d(g x, T x)=d(A, B) .
$$

To prove the uniqueness, let $x^{*}$ be another point in $A_{0}$ such that

$$
d\left(g x^{*}, T x^{*}\right)=d(A, B)
$$

If $x \neq x^{*}$, since $g \in \mathscr{G}_{A_{0}}$ and $T$ is a proximal $\psi$-contraction of the first kind, we get

$$
\begin{aligned}
d\left(x, x^{*}\right) & \leq d\left(g x, g x^{*}\right) \leq \psi\left(d\left(x, x^{*}\right)\right) \\
& <d\left(x, x^{*}\right)
\end{aligned}
$$

which is a contradiction; thus we have $x=x^{*}$.

Remark 12. If in Theorem 11 we assume $g \in \mathscr{G}_{A}$, then we get that there exists a unique $x \in A$ such that $d(g x, T x)=$ $d(A, B)$.

From Theorem 11 and the above remark, we obtain the following corollary.

Corollary 13 (see [9, Theorem 3.1]). Let $A$ and $B$ be two nonempty subsets of a complete metric space $(X, d)$. Suppose that $A_{0}$ is nonempty and closed. Assume also that the mappings $T: A \rightarrow B$ and $g: A \rightarrow A$ satisfy the following conditions:

(a) $T$ is a proximal contraction of the first kind;

(b) $g$ is an isometry; (c) $T\left(A_{0}\right) \subseteq B_{0}$;

(d) $A_{0} \subseteq g\left(A_{0}\right)$.

Then there exists a unique point $x \in A$ such that $d(g x, T x)=d(A, B)$. Moreover, for every $x_{0} \in A_{0}$ there exists a sequence $\left\{x_{n}\right\} \subseteq A$ such that $d\left(g x_{n+1}, T x_{n}\right)=d(A, B)$ for every $n \in \mathbb{N} \cup\{0\}$ and $x_{n} \rightarrow x$.

If in Theorem 11 the mapping $g$ is the identity on $A$, then we get the following corollary.

Corollary 14. Let $A$ and $B$ be two nonempty subsets of $a$ complete metric space $(X, d)$. Suppose that $A_{0}$ is nonempty and closed. Let $T: A \rightarrow B$ satisfy the following conditions:

(a) $T$ is a proximal $\psi$-contraction of the first kind;

(b) $T\left(A_{0}\right) \subseteq B_{0}$.

Then there exists a unique point $x \in A$ such that $d(x, T x)=$ $d(A, B)$. Moreover, for every $x_{0} \in A_{0}$ there exists a sequence $\left\{x_{n}\right\} \subseteq A$ such that $d\left(x_{n+1}, T x_{n}\right)=d(A, B)$ for every $n \in \mathbb{N} \cup\{0\}$ and $x_{n} \rightarrow x$.

The following theorem is our main result for proximal $\psi$ contractions of the second kind.

Theorem 15. Let $A$ and $B$ be two nonempty subsets of $a$ complete metric space $(X, d)$. Suppose that $T\left(A_{0}\right)$ is nonempty and closed. Assume also that the mappings $T: A \rightarrow B$ and $g: A \rightarrow$ A satisfy the following conditions:
(a) $T$ is a proximal $\psi$-contraction of the second kind;
(b) $T \in \mathscr{T}_{g}$;
(c) $T\left(A_{0}\right) \subseteq B_{0}$;
(d) $A_{0} \subseteq g\left(A_{0}\right)$.

Then there exists a point $x \in A$ such that $d(g x, T x)=$ $d(A, B)$. Moreover, if $T$ is injective, then the point $x$ such that $d(g x, T x)=d(A, B)$ is unique.

Proof. Similar to the proof of Theorem 11, we can find a sequence $\left\{x_{n}\right\} \subseteq A_{0}$ such that

$$
d\left(g x_{n+1}, T x_{n}\right)=d(A, B), \quad \forall n \in \mathbb{N} \cup\{0\} .
$$

Since $T$ is a proximal $\psi$-contraction of the second kind, we have

$$
d\left(\operatorname{Tg} x_{n+1}, \operatorname{Tg} x_{n}\right) \leq \psi\left(d\left(T x_{n}, T x_{n-1}\right)\right)
$$

for every $n \in \mathbb{N}$. Since $T \in \mathscr{T}_{g}$, we get

$$
d\left(T x_{n+1}, T x_{n}\right) \leq \psi\left(d\left(T x_{n}, T x_{n-1}\right)\right)
$$

for every $n \in \mathbb{N}$. Since $\psi$ is nondecreasing, we get by induction that

$$
d\left(T x_{n+1}, T x_{n}\right) \leq \psi^{n}\left(d\left(T x_{1}, T x_{0}\right)\right) .
$$

By definition of $\psi$, letting $n \rightarrow+\infty$, we obtain that

$$
\lim _{n \rightarrow+\infty} d\left(T x_{n+1}, T x_{n}\right)=0 .
$$


Similar to the proof of Theorem 11, we prove that $\left\{T x_{n}\right\}$ is a Cauchy sequence. By the completeness of $X$ and since $T\left(A_{0}\right)$ is closed, we have $T x_{n} \rightarrow T u \in B_{0}$. Moreover, there exists $z \in A_{0}$ such that

$$
d(z, T u)=d(A, B)
$$

Since $A_{0} \subseteq g\left(A_{0}\right)$, we obtain that $z=g x$ for some $x \in A_{0}$, and then

$$
d(g x, T u)=d(A, B)
$$

Again, since $T$ is a proximal $\psi$-contraction of the second kind, we get

$$
\begin{aligned}
d\left(\operatorname{Tx}, T x_{n+1}\right) & \leq d\left(\operatorname{Tg} x, \operatorname{Tg} x_{n+1}\right) \\
& \leq \psi\left(d\left(\operatorname{Tu}, T x_{n}\right)\right) \\
& \leq d\left(T u, T x_{n}\right) .
\end{aligned}
$$

Letting $n \rightarrow+\infty$, we obtain that $d\left(T x, T x_{n+1}\right) \rightarrow 0$ and hence $T x=T u$. This implies that

$$
d(g x, T x)=d(A, B) .
$$

To prove the uniqueness, let $x^{*}$ be another point in $A$ such that

$$
d\left(g x^{*}, T x^{*}\right)=d(A, B)
$$

If $x \neq x^{*}$, since $T \in \mathscr{T}_{g}$ is injective, we deduce

$$
\begin{aligned}
d\left(T x, T x^{*}\right) & \leq d\left(\operatorname{Tg} x, \operatorname{Tg} x^{*}\right) \\
& \leq \psi\left(d\left(T x, T x^{*}\right)\right) \\
& <d\left(T x, T x^{*}\right)
\end{aligned}
$$

which is a contradiction; thus we have $T x=T x^{*}$ and hence $x=x^{*}$.

From Theorem 15, we deduce the following corollary.

Corollary 16 (see [15, Theorem 3.2]). Let $A$ and $B$ be two nonempty subsets of a complete metric space $(X, d)$. Suppose that $T\left(A_{0}\right)$ is nonempty and closed. Assume also that the mappings $T: A \rightarrow B$ and $g: A \rightarrow A$ satisfy the following conditions:
(a) $T$ is a proximal contraction of the second kind;
(b) $g$ is an isometry;
(c) T preserves isometric distance with respect to $g$;
(d) $T\left(A_{0}\right) \subseteq B_{0}$;
(e) $A_{0} \subseteq g\left(A_{0}\right)$.

Then there exists a point $x \in A$ such that $d(g x, T x)=$ $d(A, B)$. Moreover, if $z \in A$ is another point for which $d(g z, T z)=d(A, B)$, then $T x=T z$.

If in Theorem 15 the mapping $g$ is the identity on $A$, then we get the following corollary.
Corollary 17. Let $A$ and $B$ be two nonempty subsets of $a$ complete metric space $(X, d)$. Suppose that $T\left(A_{0}\right)$ is nonempty and closed. Let $T: A \rightarrow B$ satisfy the following conditions:

(a) $T$ is a proximal $\psi$-contraction of the second kind;

(b) $T\left(A_{0}\right) \subseteq B_{0}$.

Then there exists a point $x \in A$ such that $d(x, T x)=$ $d(A, B)$. Moreover, if $T$ is injective on $A$, then the point $x$ such that $d(x, T x)=d(A, B)$ is unique.

The following is a theorem for weak proximal $\psi$ contractions of the first kind.

Theorem 18. Let $A$ and $B$ be two nonempty subsets of $a$ complete metric space $(X, d)$. Suppose that $A_{0}$ is nonempty and closed. Assume also that the mappings $T: A \rightarrow B$ and $g: A \rightarrow$ A satisfy the following conditions:
(a) $T$ is a weak proximal $\psi$-contraction of the first kind;
(b) $g \in \mathscr{G}_{A_{0}}$;
(c) $T\left(A_{0}\right) \subseteq B_{0}$;
(d) $A_{0} \subseteq g\left(A_{0}\right)$.

Then there exists a unique point $x \in A_{0}$ such that $d(g x, T x)=d(A, B)$. Moreover, for every $x_{0} \in A_{0}$ there exists a sequence $\left\{x_{n}\right\} \subseteq A$ such that $d\left(g x_{n+1}, T x_{n}\right)=d(A, B)$ for every $n \in \mathbb{N} \cup\{0\}$ and $x_{n} \rightarrow x$.

Proof. Let $x_{0} \in A_{0}$. Since $T\left(A_{0}\right) \subseteq B_{0}$ and $A_{0} \subseteq g\left(A_{0}\right)$, there exists $x_{1} \in A_{0}$ such that

$$
d\left(g x_{1}, T x_{0}\right)=d(A, B) .
$$

Again, for $x_{1} \in A_{0}$, there exists $x_{2} \in A_{0}$ such that

$$
d\left(g x_{2}, T x_{1}\right)=d(A, B) .
$$

By repeating this process, for $x_{n} \in A_{0}$, we can find $x_{n+1} \in A_{0}$ such that

$$
d\left(g x_{n+1}, T x_{n}\right)=d(A, B), \quad \forall n \in \mathbb{N} \cup\{0\} .
$$

Since $T$ is a weak proximal $\psi$-contraction of the first kind and $g \in \mathscr{G}_{A_{0}}$, we have

$$
\begin{aligned}
d\left(x_{n+1}, x_{n}\right) & \leq d\left(g x_{n+1}, g x_{n}\right) \\
& \leq d\left(x_{n}, x_{n-1}\right)-\psi\left(d\left(x_{n}, x_{n-1}\right)\right) \\
& \leq d\left(x_{n}, x_{n-1}\right)
\end{aligned}
$$

for every $n \in \mathbb{N}$. Let $t_{n}=d\left(x_{n}, x_{n+1}\right)$; then $\left\{t_{n}\right\}$ is a bounded nonincreasing sequence of nonnegative real numbers. Therefore, $\left\{t_{n}\right\}$ converges to $t$, where $t \geq 0$. Now let us claim that $t=0$. Suppose that $t>0$. Since $\psi \in \Phi$, we get $0<\psi(t) \leq$ $\psi\left(t_{n}\right)$, for all $n \in \mathbb{N}$. Then, we have

$$
\begin{aligned}
t_{n} & =d\left(x_{n}, x_{n+1}\right) \leq d\left(g x_{n}, g x_{n+1}\right) \\
& \leq d\left(x_{n-1}, x_{n}\right)-\psi\left(d\left(x_{n-1}, x_{n}\right)\right) \\
& =t_{n-1}-\psi\left(t_{n-1}\right) \\
& \leq t_{n-1}-\psi(t) .
\end{aligned}
$$


Inductively we obtain $t_{n+p} \leq t_{n}-p \psi(t)$, which is a contradiction for $p$ large enough. Therefore $t=0$ and hence $d\left(x_{n}, x_{n+1}\right) \rightarrow 0$.

Now let us claim that $\left\{x_{n}\right\}$ is a Cauchy sequence. Suppose it is not. Then there exist $\varepsilon>0$ and subsequences $\left\{x_{m_{k}}\right\},\left\{x_{n_{k}}\right\}$ of $\left\{x_{n}\right\}$ such that

$$
r_{k}=d\left(x_{m_{k}}, x_{n_{k}}\right) \geq \varepsilon, \quad d\left(x_{m_{k}}, x_{n_{k}-1}\right)<\varepsilon,
$$

and $n_{k}>m_{k} \geq k$, for all $k \in \mathbb{N}$. Therefore,

$$
\begin{aligned}
\varepsilon & \leq r_{k} \leq d\left(x_{m_{k}}, x_{n_{k}-1}\right)+d\left(x_{n_{k}-1}, x_{n_{k}}\right) \\
& <\varepsilon+t_{n_{k}-1} .
\end{aligned}
$$

By letting $k \rightarrow+\infty$, we have

$$
\lim _{k \rightarrow+\infty} r_{k}=\varepsilon
$$

Since

$$
\begin{aligned}
& d\left(g x_{m_{k}+1}, T x_{m_{k}}\right)=d(A, B), \\
& d\left(g x_{n_{k}+1}, T x_{n_{k}}\right)=d(A, B),
\end{aligned}
$$

and $T$ is a weak proximal $\psi$-contraction of the first kind, we obtain that

$$
\begin{aligned}
d\left(x_{m_{k}+1}, x_{n_{k}+1}\right) & \leq d\left(g x_{m_{k}+1}, g x_{n_{k}+1}\right) \\
& \leq d\left(x_{m_{k}}, x_{n_{k}}\right)-\psi\left(d\left(x_{m_{k}}, x_{n_{k}}\right)\right) .
\end{aligned}
$$

Thus,

$$
\begin{aligned}
\varepsilon & \leq r_{k} \leq d\left(x_{m_{k}}, x_{m_{k}+1}\right)+d\left(x_{m_{k}+1}, x_{n_{k}+1}\right)+d\left(x_{n_{k}+1}, x_{n_{k}}\right) \\
& =t_{m_{k}}+t_{n_{k}}+d\left(x_{m_{k}+1}, x_{n_{k}+1}\right) \\
& \leq t_{m_{k}}+t_{n_{k}}+d\left(x_{m_{k}}, x_{n_{k}}\right)-\psi\left(d\left(x_{m_{k}}, x_{n_{k}}\right)\right) \\
& \leq t_{m_{k}}+t_{n_{k}}+d\left(x_{m_{k}}, x_{n_{k}}\right)-\psi(\varepsilon) .
\end{aligned}
$$

Letting $k \rightarrow+\infty$, we have $\varepsilon \leq \varepsilon-\psi(\varepsilon)$, which is a contradiction. Therefore, $\left\{x_{n}\right\}$ is a Cauchy sequence. By the completeness of $X$ and since $A_{0}$ is closed, we have $x_{n} \rightarrow x \in$ $A_{0}$. Moreover, by the continuity of $g$, we have $g x_{n} \rightarrow g x$ and thus $g x \in A_{0}$, since $g x_{n} \in A_{0}$, for all $n \in \mathbb{N}$.

On the other hand, since $x \in A_{0}$ and $T\left(A_{0}\right) \subseteq B_{0}$, there exists $z \in A_{0}$ such that

$$
d(z, T x)=d(A, B)
$$

Again, since $T$ is a weak proximal $\psi$-contraction of the first kind, we get

$$
d\left(z, g x_{n+1}\right) \leq d\left(x, x_{n}\right)-\psi\left(d\left(x, x_{n}\right)\right) \leq d\left(x, x_{n}\right) .
$$

Letting $n \rightarrow+\infty$, we obtain that $d\left(z, g x_{n+1}\right) \rightarrow 0$ and then $z=g x$. This implies that

$$
d(g x, T x)=d(A, B)
$$

To prove the uniqueness, let $x^{*}$ be another point in $A_{0}$ such that

$$
d\left(g x^{*}, T x^{*}\right)=d(A, B) .
$$

If $x \neq x^{*}$, since $g \in \mathscr{G}_{A_{0}}$ and $T$ is a weak proximal $\psi$ contraction of the first kind, we get

$$
\begin{aligned}
d\left(x, x^{*}\right) & \leq d\left(g x, g x^{*}\right) \\
& \leq d\left(x, x^{*}\right)-\psi\left(d\left(x, x^{*}\right)\right) \\
& <d\left(x, x^{*}\right),
\end{aligned}
$$

which is a contradiction; thus we have $x=x^{*}$.

Remark 19. If in Theorem 18 we assume $g \in \mathscr{G}_{A}$, then we get that there exists a unique $x \in A$ such that $d(g x, T x)=$ $d(A, B)$.

If we take $g$ as the identity mapping on $A$ in Theorem 18, then we get the following corollary, which extends a result of Rhoades [25] to non-self-mappings.

Corollary 20. Let $A$ and $B$ be two nonempty subsets of $a$ complete metric space $(X, d)$. Suppose that $A_{0}$ is nonempty and closed. Let $T: A \rightarrow B$ satisfy the following conditions:

(a) $T$ is a weak proximal $\psi$-contraction of the first kind;

(b) $T\left(A_{0}\right) \subseteq B_{0}$.

Then there exists a unique point $x \in A_{0}$ such that $d(x, T x)=d(A, B)$. Moreover, for every $x_{0} \in A_{0}$ there exists $a$ sequence $\left\{x_{n}\right\} \subseteq A$ such that $d\left(x_{n+1}, T x_{n}\right)=d(A, B)$ for every $n \in \mathbb{N} \cup\{0\}$ and $x_{n} \rightarrow x$.

The following theorem is our main result for weak proximal $\psi$-contractions of the second kind.

Theorem 21. Let $A$ and $B$ be two nonempty subsets of $a$ complete metric space $(X, d)$. Suppose that $T\left(A_{0}\right)$ is nonempty and closed. Assume also that the mappings $T: A \rightarrow B$ and $g: A \rightarrow$ A satisfy the following conditions:

(a) $T$ is a weak proximal $\psi$-contraction of the second kind;

(b) $T \in \mathscr{T}_{g}$;

(c) $T\left(A_{0}\right) \subseteq B_{0}$;

(d) $A_{0} \subseteq g\left(A_{0}\right)$.

Then there exists a point $x \in A$ such that $d(g x, T x)=$ $d(A, B)$. Moreover, if $T$ is injective on $A$, then the point $x$ such that $d(g x, T x)=d(A, B)$ is unique.

Proof. Similar to the proof of Theorem 18, we can find a sequence $\left\{x_{n}\right\} \subseteq A_{0}$ such that

$$
d\left(g x_{n+1}, T x_{n}\right)=d(A, B), \quad \forall n \in \mathbb{N} \cup\{0\} .
$$

Since $T$ is a weak proximal $\psi$-contraction of the second kind, we have

$$
\begin{aligned}
d\left(\operatorname{Tg} x_{n+1}, T g x_{n}\right) & \leq d\left(T x_{n}, T x_{n-1}\right)-\psi\left(d\left(T x_{n}, T x_{n-1}\right)\right) \\
& \leq d\left(T x_{n}, T x_{n-1}\right)
\end{aligned}
$$


for every $n \in \mathbb{N}$. Since $T \in \mathscr{T}_{g}$, we get

$$
d\left(T x_{n+1}, T x_{n}\right) \leq d\left(\operatorname{Tg} x_{n+1}, T g x_{n}\right) \leq d\left(T x_{n}, T x_{n-1}\right)
$$

for every $n \in \mathbb{N}$. Let $t_{n}=d\left(T x_{n}, T x_{n+1}\right)$; then $\left\{t_{n}\right\}$ is a bounded nonincreasing sequence of nonnegative real numbers. Therefore, $\left\{t_{n}\right\}$ converges to $t$, where $t \geq 0$. Now let us claim that $t=0$. Suppose that $t>0$. Since $\psi \in \Phi$, we get $0<\psi(t) \leq \psi\left(t_{n}\right)$, for all $n \in \mathbb{N}$. Then, we have

$$
\begin{aligned}
t_{n} & =d\left(T x_{n}, T x_{n+1}\right) \leq d\left(\operatorname{Tg} x_{n}, T g x_{n+1}\right) \\
& \leq d\left(T x_{n-1}, T x_{n}\right)-\psi\left(d\left(T x_{n-1}, T x_{n}\right)\right) \\
& =t_{n-1}-\psi\left(t_{n-1}\right) \\
& \leq t_{n-1}-\psi(t) .
\end{aligned}
$$

Inductively we obtain $t_{n+p} \leq t_{n}-p \psi(t)$, which is a contradiction for $p$ large enough. Therefore $t=0$ and hence $d\left(T x_{n}, T x_{n+1}\right) \rightarrow 0$.

Now let us claim that $\left\{T x_{n}\right\}$ is a Cauchy sequence. Suppose it is not. Then there exist $\varepsilon>0$ and subsequences $\left\{T x_{m_{k}}\right\},\left\{T x_{n_{k}}\right\}$ of $\left\{T x_{n}\right\}$ such that

$$
r_{k}=d\left(T x_{m_{k}}, T x_{n_{k}}\right) \geq \varepsilon, \quad d\left(T x_{m_{k}}, T x_{n_{k}-1}\right)<\varepsilon,
$$

and $n_{k}>m_{k} \geq k$, for all $k \in \mathbb{N}$. Therefore, we get

$$
\begin{aligned}
\varepsilon & \leq r_{k} \leq d\left(T x_{m_{k}}, T x_{n_{k}-1}\right)+d\left(T x_{n_{k}-1}, T x_{n_{k}}\right) \\
& <\varepsilon+t_{n_{k}-1} .
\end{aligned}
$$

By letting $k \rightarrow+\infty$, we have

$$
\lim _{k \rightarrow+\infty} r_{k}=\varepsilon
$$

Since

$$
\begin{aligned}
& d\left(g x_{m_{k}+1}, T x_{m_{k}}\right)=d(A, B), \\
& d\left(g x_{n_{k}+1}, T x_{n_{k}}\right)=d(A, B),
\end{aligned}
$$

and $T$ is a weak proximal $\psi$-contraction of the second kind, we obtain that

$$
\begin{aligned}
d\left(T x_{m_{k}+1}, T x_{n_{k}+1}\right) & \leq d\left(\operatorname{Tg} x_{m_{k}+1}, \operatorname{Tg} x_{n_{k}+1}\right) \\
& \leq d\left(T x_{m_{k}}, T x_{n_{k}}\right)-\psi\left(d\left(T x_{m_{k}}, T x_{n_{k}}\right)\right) .
\end{aligned}
$$

Thus,

$$
\begin{aligned}
\varepsilon \leq & r_{k} \leq d\left(T x_{m_{k}}, T x_{m_{k}+1}\right)+d\left(T x_{m_{k}+1}, T x_{n_{k}+1}\right) \\
& +d\left(T x_{n_{k}+1}, T x_{n_{k}}\right) \\
= & t_{m_{k}}+t_{n_{k}}+d\left(T x_{m_{k}+1}, T x_{n_{k}+1}\right) \\
\leq & t_{m_{k}}+t_{n_{k}}+d\left(T x_{m_{k}}, T x_{n_{k}}\right)-\psi\left(d\left(T x_{m_{k}}, T x_{n_{k}}\right)\right) \\
\leq & t_{m_{k}}+t_{n_{k}}+d\left(T x_{m_{k}}, T x_{n_{k}}\right)-\psi(\varepsilon) .
\end{aligned}
$$

Letting $k \rightarrow+\infty$, we have $\varepsilon \leq \varepsilon-\psi(\varepsilon)$, which is a contradiction. Therefore, $\left\{T x_{n}\right\}$ is a Cauchy sequence. By the completeness of $X$ and since $T\left(A_{0}\right)$ is closed, we have $T x_{n} \rightarrow$ $T u \in B_{0}$. Moreover, there exists $z \in A_{0}$ such that

$$
d(z, T u)=d(A, B) .
$$

Since $A_{0} \subseteq g\left(A_{0}\right)$, we obtain that $z=g x$ for some $x \in A_{0}$, and then

$$
d(g x, T u)=d(A, B)
$$

Again, since $T$ is a weak proximal $\psi$-contraction of the second kind, we get

$$
\begin{aligned}
d\left(T x, T x_{n+1}\right) & \leq d\left(\operatorname{Tg} x, \operatorname{Tg} x_{n+1}\right) \\
& \leq d\left(T u, T x_{n}\right)-\psi\left(d\left(T u, T x_{n}\right)\right) \\
& \leq d\left(T u, T x_{n}\right) .
\end{aligned}
$$

Letting $n \rightarrow+\infty$, we obtain that $d\left(T x, T x_{n+1}\right) \rightarrow 0$ and hence $T x=T u$. This implies that

$$
d(g x, T x)=d(A, B) .
$$

To prove the uniqueness, let $x^{*}$ be another point in $A$ such that

$$
d\left(g x^{*}, T x^{*}\right)=d(A, B) .
$$

If $x \neq x^{*}$, since $T \in \mathscr{T}_{g}$ is injective on $A$, we have

$$
\begin{aligned}
d\left(T x, T x^{*}\right) & \leq d\left(\operatorname{Tg} x, \operatorname{Tg} x^{*}\right) \\
& \leq d\left(T x, T x^{*}\right)-\psi\left(d\left(T x, T x^{*}\right)\right) \\
& <d\left(T x, T x^{*}\right)
\end{aligned}
$$

which is a contradiction; thus we have $T x=T x^{*}$ and hence $x=x^{*}$.

If in Theorem 21 the mapping $g$ is the identity on $A$, we get the following corollary.

Corollary 22. Let $A$ and $B$ be two nonempty subsets of $a$ complete metric space $(X, d)$. Suppose that $T\left(A_{0}\right)$ is nonempty and closed. Let $T: A \rightarrow B$ satisfy the following conditions:

(a) $T$ is a weak proximal $\psi$-contraction of the second kind;

(b) $T\left(A_{0}\right) \subseteq B_{0}$.

Then there exists a point $x \in A$ such that $d(x, T x)=$ $d(A, B)$. Moreover, if $T$ is injective on $A$, then the point $x$ such that $d(x, T x)=d(A, B)$ is unique.

\section{Best Proximity Point Theorem for $g$-Weak Contractions}

The following result is a best proximity point theorem for $g$ weak contractions. Recall that a non-self-mapping $T: A \rightarrow$ $B$ is $g$-weakly contractive if there exists $\psi \in \Phi_{c}$ such that $d(T x, T y) \leq d(g x, g y)-\psi(d(g x, g y))$, for all $x, y \in A$, where $g: A \rightarrow A$. 
Theorem 23. Let $A$ and $B$ be closed subsets of a complete metric space $(X, d)$ such that $A_{0}, B_{0} \neq \emptyset$ and the pair $(A, B)$ has the weak $P$-property. Suppose that the mappings $g: A \rightarrow A$ and $T: A \rightarrow B$ satisfy the following conditions:
(a) $T$ is a $g$-weak contraction;
(b) $T\left(A_{0}\right) \subset B_{0}$;
(c) $A_{0} \subset g\left(A_{0}\right)$.

Then, there exists an element $x^{*} \in A_{0}$ such that $d\left(g x^{*}, T x^{*}\right)=d(A, B)$. Further, if $g$ is one to one then we have a unique element $x^{*} \in A$ such that $d\left(g x^{*}, T x^{*}\right)=d(A, B)$.

Proof. Let $x_{0}$ be an element of $A_{0}$. In light of the fact that $T\left(A_{0}\right) \subset B_{0}$ and $A_{0} \subset g\left(A_{0}\right)$, it is ensured that there exists an element $x_{1} \in A_{0}$ such that

$$
d\left(g x_{1}, T x_{0}\right)=d(A, B) .
$$

Again, in view of the fact that $T\left(A_{0}\right) \subset B_{0}$ and $A_{0} \subset g\left(A_{0}\right)$, it is guaranteed that there exists an element $x_{2} \in A_{0}$ such that

$$
d\left(g x_{2}, T x_{1}\right)=d(A, B) .
$$

Continuing this process, we can find a sequence $\left\{x_{n}\right\}$ in $A_{0}$ such that

$$
d\left(g x_{n}, T x_{n-1}\right)=d(A, B), \quad \forall n \in \mathbb{N} .
$$

Since $(A, B)$ has the weak $P$-property, we conclude that

$$
d\left(g x_{n}, g x_{n+1}\right) \leq d\left(T x_{n-1}, T x_{n}\right), \quad \forall n \in \mathbb{N} .
$$

Now, as $T$ is a $g$-weak contraction, we get

$$
\begin{aligned}
d\left(g x_{n}, g x_{n+1}\right) & \leq d\left(T x_{n-1}, T x_{n}\right) \\
& \leq d\left(g x_{n-1}, g x_{n}\right)-\psi\left(d\left(g x_{n-1}, g x_{n}\right)\right),
\end{aligned}
$$

where $\psi \in \Phi_{c}$ (see Definition 8). If we set $t_{n}=d\left(g x_{n}, g x_{n+1}\right)$, then $\left\{t_{n}\right\}$ is a nonincreasing sequence of nonnegative real numbers and hence converges. Let $t \geq 0$ be the limit of the sequence $\left\{t_{n}\right\}$. Now let us claim that $t=0$. Suppose that $t>0$. Since $\psi$ is a nondecreasing function, we deduce that $\psi\left(t_{n}\right) \geq \psi(t)>0$, for all $n \in \mathbb{N}$. Then for any positive integer $n$, by (72), we get that

$$
t_{n+1} \leq t_{n}-\psi(t) .
$$

Now, for all $n>t_{1} / \psi(t)$, by (73), we obtain that

$$
t_{n+1} \leq t_{1}-n \psi(t)<0,
$$

a contradiction. Therefore $t=0$ and hence the sequence $\left\{d\left(g x_{n}, g x_{n+1}\right)\right\}$ converges to 0 . As

$$
d\left(g x_{n}, g x_{n+1}\right) \leq d\left(T x_{n-1}, T x_{n}\right) \leq d\left(g x_{n-1}, g x_{n}\right),
$$

we deduce that the sequence $\left\{d\left(T x_{n-1}, T x_{n}\right)\right\}$ converges to 0 . Now, let us prove that $\left\{T x_{n}\right\}$ is a Cauchy sequence. Let $\varepsilon>0$ be given and we choose a positive integer $n(\varepsilon)$ such that

$$
d\left(T x_{n}, T x_{n+1}\right) \leq \min \left\{\frac{\varepsilon}{2}, \psi\left(\frac{\varepsilon}{2}\right)\right\},
$$

for all $n \geq n(\varepsilon)$. Fix $n \geq n(\varepsilon)$ and let

$$
A(n, \varepsilon):=\left\{x \in A: d\left(T x_{n}, T x\right) \leq \varepsilon\right\} .
$$

Now, it is asserted that if $x \in A(n, \varepsilon)$ and $u \in A$ is such that $d(g u, T x)=d(A, B)$, then $u \in A(n, \varepsilon)$. First, we note that as $d\left(g x_{n+1}, T x_{n}\right)=d(A, B)$, then by the weak $P$-property $d\left(g x_{n+1}, g u\right) \leq d\left(T x_{n}, T x\right)$. Two cases will be considered to establish this fact. Precisely, if $d\left(g x_{n+1}, g u\right) \leq \varepsilon / 2$, then it follows that

$$
\begin{aligned}
d\left(T x_{n}, T u\right) & \leq d\left(T x_{n}, T x_{n+1}\right)+d\left(T x_{n+1}, T u\right) \\
& \leq \frac{\varepsilon}{2}+d\left(g x_{n+1}, g u\right)-\psi\left(d\left(g x_{n+1}, g u\right)\right) \\
& \leq \frac{\varepsilon}{2}+d\left(g x_{n+1}, g u\right) \leq \varepsilon
\end{aligned}
$$

On the other hand if $\varepsilon / 2<d\left(g x_{n+1}, g u\right) \leq \varepsilon$, then it follows that

$$
\begin{aligned}
d\left(T x_{n}, T u\right) & \leq d\left(T x_{n}, T x_{n+1}\right)+d\left(T x_{n+1}, T u\right) \\
& \leq \psi\left(\frac{\varepsilon}{2}\right)+d\left(g x_{n+1}, g u\right)-\psi\left(d\left(g x_{n+1}, g u\right)\right) \\
& \leq \psi\left(\frac{\varepsilon}{2}\right)+d\left(g x_{n+1}, g u\right)-\psi\left(\frac{\varepsilon}{2}\right) \\
& =d\left(g x_{n+1}, g u\right) \leq \varepsilon
\end{aligned}
$$

So, $u \in A(n, \varepsilon)$. Now, we prove that

$$
x_{n+m} \in A(n, \varepsilon) \text {, }
$$

for all $m \geq 1$. From $x_{n} \in A(n, \varepsilon)$ and $d\left(g x_{n+1}, T x_{n}\right)=d(A, B)$, we deduce that $x_{n+1} \in A(n, \varepsilon)$; that is (80) holds for $m=1$. Now, we assume that (80) holds for some $m \geq 1$. From, $x_{n+m} \in A(n, \varepsilon)$ and $d\left(g x_{n+m+1}, T x_{n+m}\right)=d(A, B)$, we deduce that $x_{n+m+1} \in A(n, \varepsilon)$; that is (80) holds for $m+1$ and hence for all $m \geq 1$. Thus, it follows that $\left\{T x_{n}\right\}$ is a Cauchy sequence. From the completeness of the space $X$, the sequence $\left\{T x_{n}\right\}$ converges to some element $y^{*} \in B$. From $d\left(g x_{n+1}, g x_{m+1}\right) \leq$ $d\left(T x_{n}, T x_{m}\right)$, we deduce that $\left\{g x_{n}\right\}$ is also a Cauchy sequence. As $A$ is a complete subspace of $X$, then there exists $z \in A$ such that $g x_{n} \rightarrow z$. Therefore, we have

$$
d\left(z, y^{*}\right)=\lim _{n \rightarrow+\infty} d\left(g x_{n+1}, T x_{n}\right)=d(A, B),
$$

and so $z \in A_{0}$. In light of the fact that $A_{0}$ is contained in $g\left(A_{0}\right)$, there is $x^{*} \in A_{0}$ such that $z=g x^{*}$. Since $T\left(A_{0}\right) \subset B_{0}$, there exists an element $\bar{x} \in A_{0}$ such that

$$
d\left(g \bar{x}, T x^{*}\right)=d(A, B) .
$$

In view of the fact that $T$ is a $g$-weak contraction and $(A, B)$ has the weak $P$-property and the continuity of $\psi$ at $t=0$, we get

$$
\begin{aligned}
d\left(g x_{n+1}, g \bar{x}\right) & \leq d\left(T x_{n}, T x^{*}\right) \\
& \leq d\left(g x_{n+1}, g x^{*}\right)-\psi\left(d\left(g x_{n+1}, g x^{*}\right)\right) .
\end{aligned}
$$


Letting $n \rightarrow+\infty$, it follows that $g \bar{x}=g x^{*}$. Thus, we conclude that $d\left(g x^{*}, T x^{*}\right)=d(A, B)$.

To assert the uniqueness, let us assume that $z^{*} \in A$ is another element such that $d\left(g z^{*}, T z^{*}\right)=d(A, B)$. Then

$$
\begin{aligned}
d\left(g x^{*}, g z^{*}\right) & \leq d\left(T x^{*}, T z^{*}\right) \\
& \leq d\left(g x^{*}, g z^{*}\right)-\psi\left(d\left(g x^{*}, g z^{*}\right)\right),
\end{aligned}
$$

from which it follows that $g x^{*}=g z^{*}$ and hence $z^{*} \in g^{-1} g x^{*}$. If $g$ is one to one then we deduce the uniqueness.

Remark 24. From the proof of Theorem 23, we obtain that the method for getting the sequence $\left\{g x_{n}\right\}$, that is the relation $d\left(g x_{n}, g x_{n+1}\right)=d\left(T x_{n-1}, T x_{n}\right)$, also gives an iterative algorithm for computing solutions of coincidence equations.

If in Theorem 23 the mapping $g$ is the identity on $A$, then yields the following result which is a generalization of a result due to Rhoades [25] to non-self-mappings.

Corollary 25. Let $A$ and $B$ be closed subsets of a complete metric space $(X, d)$ such that $A_{0}, B_{0} \neq \emptyset$ and the pair $(A, B)$ has the weak P-property. Suppose that the mapping $T: A \rightarrow B$ satisfies the following conditions:

(i) $T$ is a g-weak contraction;

(ii) $T\left(A_{0}\right) \subset B_{0}$.

Then, there exists a unique element $x^{*} \in A$ such that $d\left(x^{*}, T x^{*}\right)=d(A, B)$. Further, for any fixed element $x_{0} \in A_{0}$, the iterative sequence $\left\{x_{n}\right\}$, defined by $d\left(x_{n+1}, T x_{n}\right)=d(A, B)$, converges to the element $x^{*}$.

Example 26. Consider $X=\mathbb{R}^{2}$ with the usual metric. Let us define

$$
\begin{aligned}
& A:=\left\{(x, y) \in \mathbb{R}^{2}: x=0, y \geq 0\right\}, \\
& B:=\left\{(x, y) \in \mathbb{R}^{2}: x=1, y \geq 0\right\} .
\end{aligned}
$$

Then $A$ and $B$ are nonempty closed subsets of $X$ and $A_{0}=A$ and $B_{0}=B$. Note that $d(A, B)=1$. Let $g: A \rightarrow A$ and $T: A \rightarrow B$ be defined as $g(0, x)=(0,2 x)$ and $T(0, x)=$ $(1, x /(1+x))$. Define $\psi:[0,+\infty) \rightarrow[0,+\infty)$ by $\psi(t)=$ $t^{2} /(1+t)$, for all $t \geq 0$. Then, $T$ is a $g$-weak contraction. As $(A, B)$ has the weak $P$-property and $g$ is one to one, we obtain that $(0,0) \in A$ is the unique $g$-best proximity point of $T$; that is, $d(g(0,0), T(0,0))=d(A, B)$.

The following example shows that the weak $P$-property in Theorem 23 cannot be relaxed; that is, a $g$-weakly contractive mapping $T: A \rightarrow B$ may not have a $g$-best proximity point in $A$ if the pair $(A, B)$ does not have the weak $P$-property, where $A$ and $B$ are nonempty closed subsets of a complete metric space $X$.

Example 27. Consider $X=\mathbb{R}$ with the usual metric, $A=$ $\{-10,10\}$ and $B=\{-2,2\}$. Then $A$ and $B$ are nonempty closed subsets of $X$ with $A_{0}=A$ and $B_{0}=B$. Note that $d(A, B)=8$.
Let $T: A \rightarrow B$ be a mapping given by $T(-10)=2$ and $T(10)=-2$. It is easy to see that $T: A \rightarrow B$ is a contraction mapping with $T\left(A_{0}\right) \subset B_{0}$ and hence it is $g$ weakly contractive, where $g$ is the identity mapping. Since $d(x, T x)=12>8=d(A, B)$, for all $x \in A$, then $T$ has no $g$-best proximity points. It is worth noting that the pair $(A, B)$ does not have the weak $P$-property.

\section{Acknowledgment}

The authors thank the referees for providing useful comments and suggestions that improved the paper. This article was funded by the Deanship of Scientific Research (DSR), King Abdulaziz University, Jeddah. The first and second authors acknowledge with thanks DSR for financial support.

\section{References}

[1] W. A. Kirk and B. Sims, Eds., Handbook of Metric Fixed Point Theory, Kluwer Academic Publishers, Dordrecht, The Netherlands, 2001.

[2] B. E. Rhoades, "A comparison of various definitions of contractive mappings," Transactions of the American Mathematical Society, vol. 226, pp. 257-290, 1977.

[3] Ya. I. Alber and S. Guerre-Delabriere, "Principle of weakly contractive maps in Hilbert spaces," in New Results in Operator Theory and its Applications, vol. 98, pp. 7-22, Birkhäauser, Basel, Switzerland, 1997.

[4] K. Fan, "Extensions of two fixed point theorems of F. E. Browder," Mathematische Zeitschrift, vol. 112, no. 3, pp. 234-240, 1969.

[5] M. A. Al-Thagafi and N. Shahzad, "Convergence and existence results for best proximity points," Nonlinear Analysis, Theory, Methods and Applications, vol. 70, no. 10, pp. 3665-3671, 2009.

[6] M. Derafshpour, S. Rezapour, and N. Shahzad, "Best proximity points of cyclic $\phi$-contractions in ordered metric spaces," Topological Methods in Nonlinear Analysis, vol. 37, no. 1, pp. 193202, 2011.

[7] C. Di Bari, T. Suzuki, and C. Vetro, "Best proximity points for cyclic Meir-Keeler contractions," Nonlinear Analysis, Theory, Methods and Applications, vol. 69, no. 11, pp. 3790-3794, 2008.

[8] A. A. Eldred and P. Veeramani, "Existence and convergence of best proximity points," Journal of Mathematical Analysis and Applications, vol. 323, no. 2, pp. 1001-1006, 2006.

[9] A. Fernández-León, "Best proximity points for proximal contractions," http://arxiv.org/abs/1207.4349, 2012.

[10] M. Gabeleh and N. Shahzad, "Existence and convergence theorems of best proximity points," Journal of Applied Mathematics, vol. 2013, Article ID 101439, 6 pages, 2013.

[11] W. A. Kirk, S. Reich, and P. Veeramani, "Proximinal retracts and best proximity pair theorems," Numerical Functional Analysis and Optimization, vol. 24, no. 7-8, pp. 851-862, 2003.

[12] S. Sadiq Basha, "Global optimal approximate solutions," Optimization Letters, vol. 5, no. 4, pp. 639-645, 2011.

[13] S. Sadiq Basha, "Best proximity point theorems," Journal of Approximation Theory, vol. 163, no. 11, pp. 1772-1781, 2011.

[14] S. Sadiq Basha, "Best proximity point theorems: an exploration of a common solution to approximation and optimization problems," Applied Mathematics and Computation, vol. 218, no. 19, pp. 9773-9780, 2012. 
[15] S. Sadiq Basha, "Best proximity points: global optimal approximate solutions," Journal of Global Optimization, vol. 49, no. 1 , pp. 15-21, 2011.

[16] S. Sadiq Basha, "Best proximity point theorems for generalized proximal contractions," Fixed Point Theory and Applications, vol. 2012, p. 42, 2012.

[17] S. Sadiq Basha, N. Shahzad, and R. Jeyaraj, "Best proximity points: approximation and optimization," Optimization Letters, vol. 7, no. 1, pp. 145-155, 2013.

[18] S. Sadiq Basha, N. Shahzad, and R. Jeyaraj, "Best proximity point theorems for reckoning optimal approximate solutions," Fixed Point Theory and Applications, vol. 2012, p. 202, 2012.

[19] S. Sadiq Basha, N. Shahzad, and R. Jeyaraj, "Common best proximity points: global optimal solutions," Journal of Optimization Theory and Applications, vol. 148, no. 1, pp. 69-78, 2011.

[20] S. Sadiq Basha and P. Veeramani, "Best proximity pair theorems for multifunctions with open fibres," Journal of Approximation Theory, vol. 103, no. 1, pp. 119-129, 2000.

[21] W. Sanhan, C. Mongkolkeha, and P. Kumam, "Generalized proximal $\psi$-contraction mappings and best proximity points," Abstract and Applied Analysis, vol. 2012, Article ID 896912, 19 pages, 2012.

[22] V. Sankar Raj, "A best proximity point theorem for weakly contractive non-self-mappings," Nonlinear Analysis, Theory, Methods and Applications, vol. 74, no. 14, pp. 4804-4808, 2011.

[23] C. Vetro, "Best proximity points: convergence and existence theorems for P-cyclic mappings," Nonlinear Analysis, Theory, Methods and Applications, vol. 73, no. 7, pp. 2283-2291, 2010.

[24] J. Zhang, Y. Su, and Q. Cheng, "A note on 'A best proximity point theorem for Geraghty-contractions"', Fixed Point Theory and Applications, vol. 2013, p. 99, 2013.

[25] B. E. Rhoades, "Some theorems on weakly contractive maps," Nonlinear Analysis, Theory, Methods and Applications, vol. 47, no. 4, pp. 2683-2693, 2001. 


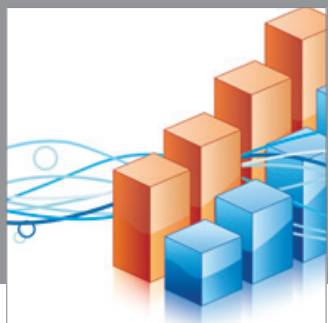

Advances in

Operations Research

mansans

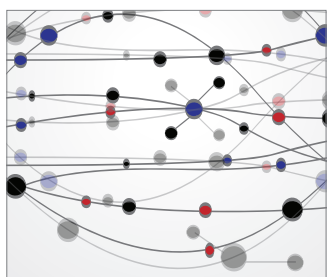

The Scientific World Journal
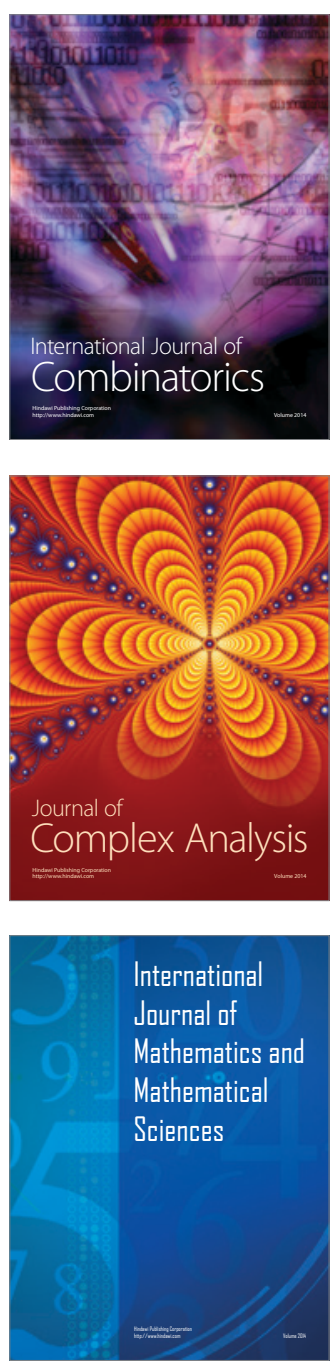
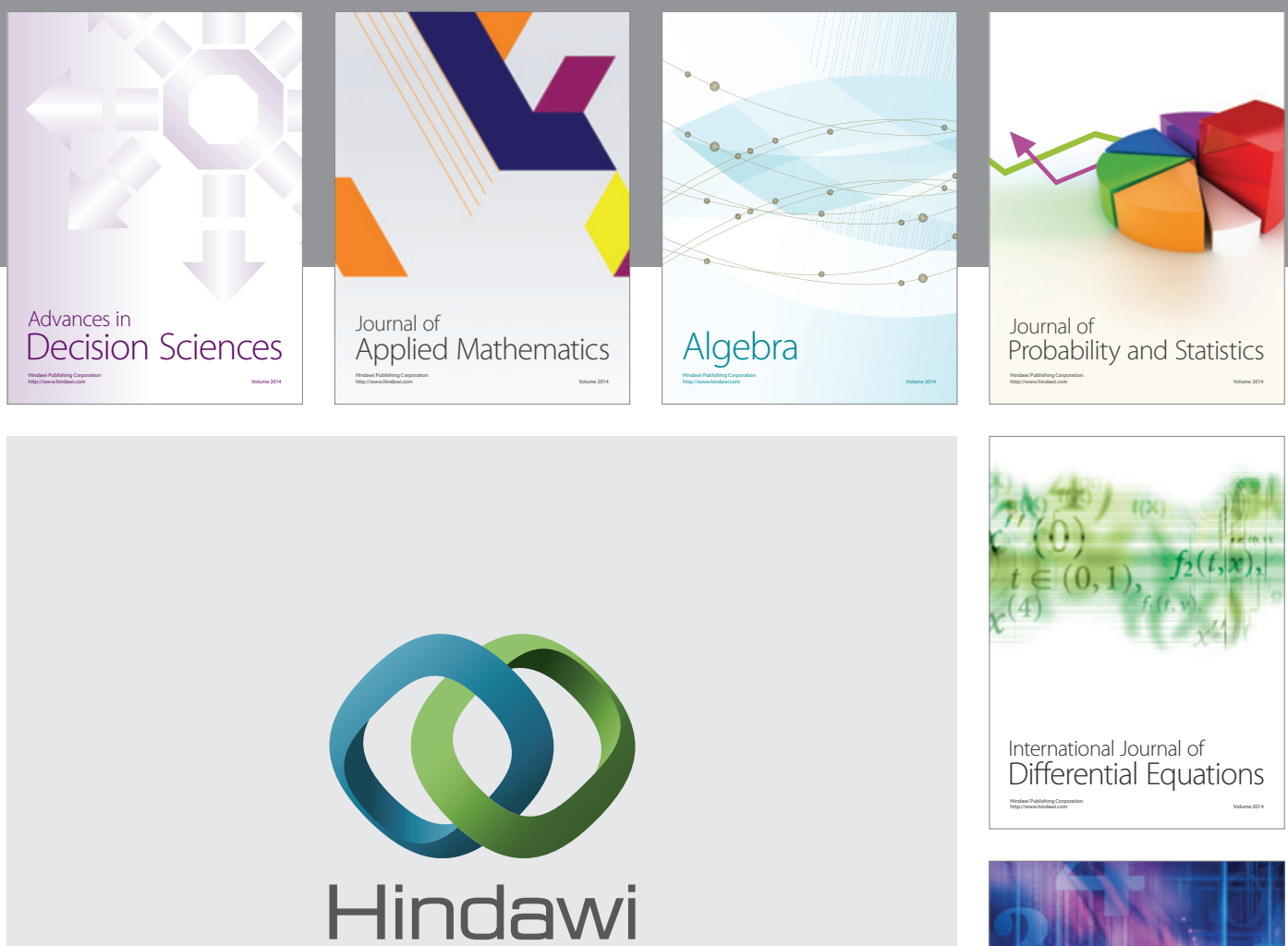

Submit your manuscripts at http://www.hindawi.com
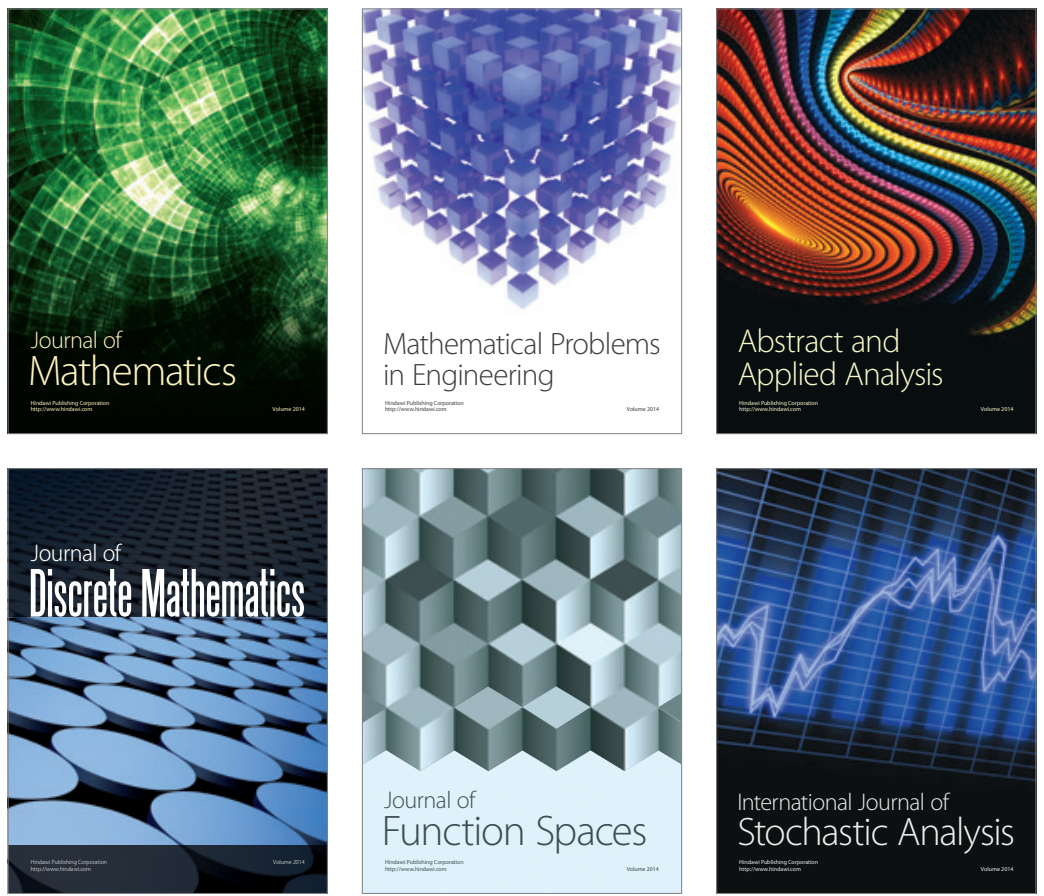

Journal of

Function Spaces

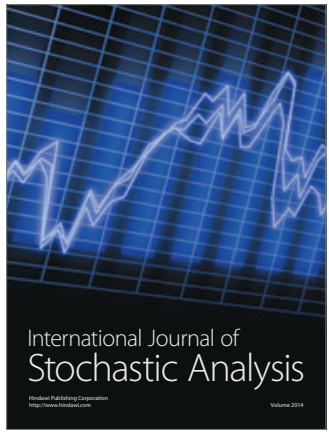

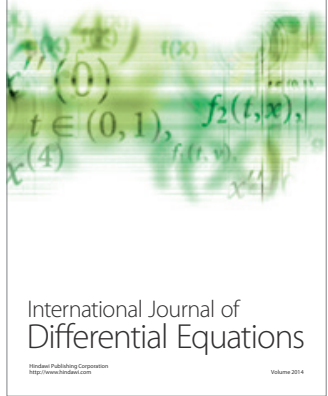
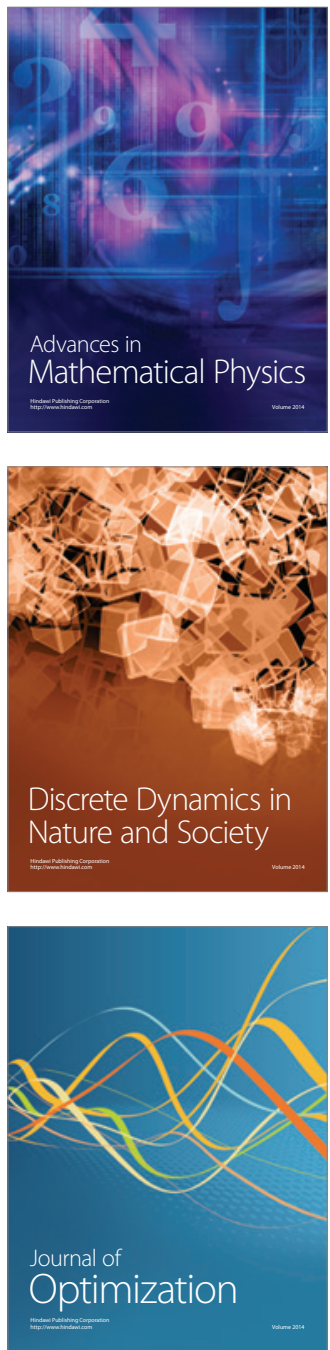